\title{
Ten-year cardiovascular risk in diabetes patients without obstructive coronary artery disease: a retrospective Western Denmark cohort study
}

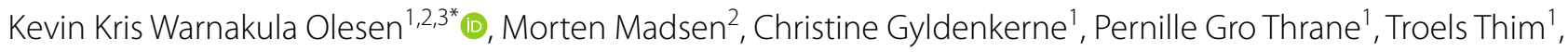
Lisette Okkels Jensen ${ }^{4}$, Hans Erik Bøtker ${ }^{1}$, Henrik Toft Sørensen ${ }^{2}$ and Michael Maeng ${ }^{1}$

\begin{abstract}
Background: Diabetes patients without obstructive coronary artery disease as assessed by coronary angiography have a low risk of myocardial infarction, but their myocardial infarction risk may still be higher than the general population. We examined the 10-year risks of myocardial infarction, ischemic stroke, and death in diabetes patients without obstructive coronary artery disease according to coronary angiography, compared to risks in a matched general population cohort.

Methods: We included all diabetes patients without obstructive coronary artery disease examined by coronary angiography from 2003 to 2016 in Western Denmark. Patients were matched by age and sex with a cohort from the Western Denmark general population without a previous myocardial infarction or coronary revascularization. Outcomes were myocardial infarction, ischemic stroke, and death. Ten-year cumulative incidences were computed. Adjusted hazard ratios (HR) then were computed using stratified Cox regression with the general population as reference.

Results: We identified 5734 diabetes patients without obstructive coronary artery disease and 28,670 matched individuals from the general population. Median follow-up was 7 years. Diabetes patients without obstructive coronary artery disease had an almost similar 10 -year risk of myocardial infarction (3.2\% vs $2.9 \%$, adjusted $\mathrm{HR} 0.93,95 \% \mathrm{Cl}$ 0.72-1.20) compared to the general population, but had an increased risk of ischemic stroke (5.2\% vs $2.2 \%$, adjusted HR 1.87, 95\% Cl 1.47-2.38) and death (29.6\% vs 17.8\%, adjusted HR 1.24, 95\% Cl 1.13-1.36).

Conclusions: Patients with diabetes and no obstructive coronary artery disease have a 10-year risk of myocardial infarction that is similar to that found in the general population. However, they still remain at increased risk of ischemic stroke and death.
\end{abstract}

Keywords: Coronary angiography, Coronary artery disease, Death, Diabetes, Ischemic stroke, Myocardial infarction

*Correspondence: kevole@clin.au.dk

1 Department of Cardiology, Aarhus University Hospital, Palle Juul-Jensens Boulevard 99, 8200 Aarhus N, Denmark

Full list of author information is available at the end of the article

\section{Introduction}

Patients with diabetes are considered to have a greater risk of cardiovascular disease than individuals without diabetes [1]. Diabetes patients with coronary artery disease $(\mathrm{CAD})$ also have a substantially higher risk of subsequent adverse cardiovascular outcomes compared to non-diabetes patients with CAD [2]. Still, earlier studies have found that diabetes and non-diabetes patients

(c) The Author(s) 2021. This article is licensed under a Creative Commons Attribution 4.0 International License, which permits use, sharing, adaptation, distribution and reproduction in any medium or format, as long as you give appropriate credit to the original author(s) and the source, provide a link to the Creative Commons licence, and indicate if changes were made. The images or other third party material in this article are included in the article's Creative Commons licence, unless indicated otherwise in a credit line to the material. If material is not included in the article's Creative Commons licence and your intended use is not permitted by statutory regulation or exceeds the permitted use, you will need to obtain permission directly from the copyright holder. To view a copy of this licence, visit http://creativeco mmons.org/licenses/by/4.0/. The Creative Commons Public Domain Dedication waiver (http://creativecommons.org/publicdomain/ zero/1.0/) applies to the data made available in this article, unless otherwise stated in a credit line to the data. 
have the same low risk of myocardial infarction (MI), in the absence of obstructive CAD, as assessed by coronary angiography (CAG) or coronary computed tomography angiography [2-4]. However, prior studies compared symptomatic routine clinical care patients referred for coronary examination and were limited by lack of generalizability to the general population. The cardiovascular risk of diabetes patients without CAD compared to the general population remains largely unknown.

We hypothesized that diabetes patients without obstructive CAD have a risk of MI similar to that of the general population. To address this question, we conducted a cohort study in which we compared diabetes patients without CAD, as assessed by CAG, in Western Denmark to an age- and sex matched cohort without history of MI from the Western Denmark general population.

\section{Methods}

\section{Databases}

We conducted a retrospective, registry-based cohort study. Denmark has a free tax-supported health care system. This cohort study was based on data from several databases. The Western Denmark Heart Registry has recorded every CAG performed in Western Denmark since 1999 [5]. The Danish Civil Registration System contains information on the vital status of every individual residing in Denmark [6]. Each resident is assigned a personal unique 10-digit number at birth or upon immigration. This identifier is used in every registry in Denmark, allowing linkage of patient information among health care registries. The Danish National Patient Registry has recorded each Danish resident's contacts with the public hospital system, including outpatient clinics, since 1977. This registry contains information on primary and secondary discharge diagnoses based on ICD-8 and ICD-10 codes [7]. The Danish Prescription Registry has registered every prescription redeemed at any Danish pharmacy since 1994 [8].

\section{CAG diabetes cohort}

We reviewed every patient examined using CAG between January 1, 2003 and December 31, 2016 in Western Denmark (Fig. 1). If the same patient received multiple examinations, the first CAG was considered the index procedure. We excluded patients with a previous history

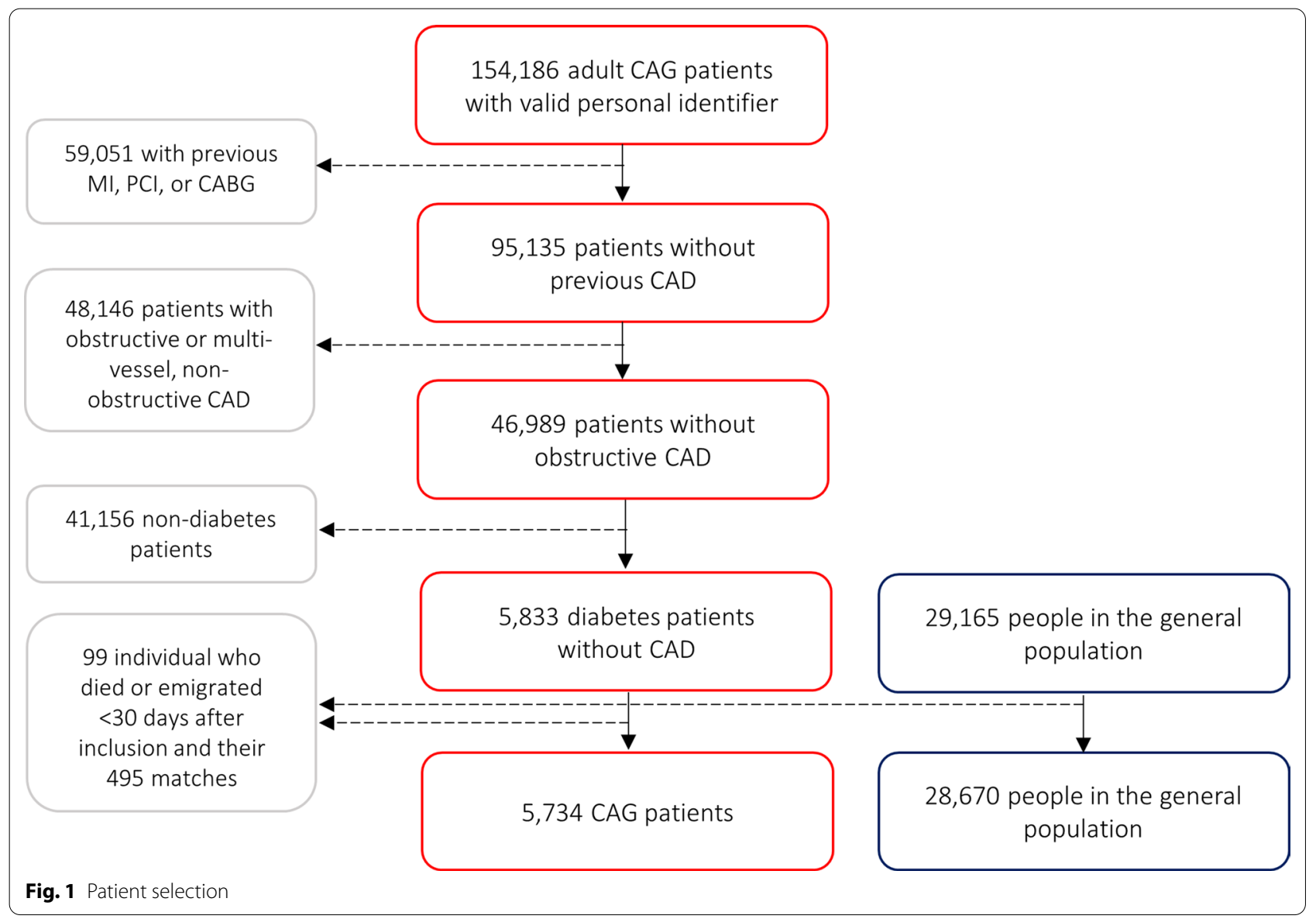


of MI, percutaneous coronary intervention (PCI), and/ or coronary artery bypass grafting (CABG) recorded in either the Western Denmark Heart Registry or the Danish National Patient Registry prior to CAG. Patients with obstructive CAD ( $\geq 50 \%$ coronary stenosis in $\geq 1$ coronary vessel) or diffuse CAD (defined as non-obstructive CAD in $\geq 2$ coronary vessels) also were excluded. Finally, only patients with either registered diabetes prior to inclusion in the Danish National Patient Registry or the Western Denmark Heart Registry, or in active anti-diabetes treatment $[\geq 1$ redeemed prescription(s) registered in the Danish Prescription Registry 6 months before or 30 days after CAG] were included (Additional file 1: Table S1).

\section{General population cohort}

Diabetes patients were frequency matched by sex and age in a 1:5 ratio with individuals drawn from the Western Denmark general population who had no previous history of MI, PCI, or CABG in the Danish National Patient Registry at the time of matching. Replacement was allowed during matching [9].

\section{Co-medications}

Active drug treatment was defined as redeeming $\geq 1$ prescription(s) 6 months before or 30 days after study inclusion (Additional file 1: Table S1) [8]. Diabetes duration was estimated as the time from the first insulin or non-insulin prescription dispensation recorded in the Danish National Prescription Registry until start of follow-up [8]. Duration of diabetes as categorized as $0-4$ years, $5-9$ years, and $\geq 10$ years.

\section{Comorbidity}

Disease burden prior to start of follow-up was ascertained from the Danish National Patient Registry using inpatient and outpatient primary and secondary discharge diagnoses (Additional file 1: Table S1). In the matched general population sample, diabetes was identified by combining discharge diagnoses and dispensed diabetes prescriptions.

\section{Outcomes}

MI was defined as a primary or secondary discharge diagnosis during an acute hospitalization registered in the Danish National Patient Registry (Additional file 1: Table S1) [10]. Ischemic stroke was defined as a primary or secondary discharge diagnosis recorded in the Danish National Patient Registry [11]. Deaths were identified from the Civil Registration System [6].

\section{Statistical analysis}

Follow-up started 30 days after study inclusion to reduce the risk of double-registration of CAG-related ischemic events. People with $<30$ days of follow-up, due either to death or emigration, were excluded from analyses, as well as their matched counterparts. Followup continued until an outcome, death, emigration, or end of follow-up (December 31, 2018). Follow-up was capped at 10.0 years, corresponding to the 75 th percentile of overall follow-up. Events beyond 10 years were censored. Cumulative incidence proportion (CIP) curves were constructed. Ten-year CIP curves and risk differences (RDs) were computed, accounting for the competing risk of death in the case of MI and ischemic stroke. A stratified Cox regression analysis was used to compute the HR of death with $95 \%$ CI. The proportional hazards assumption was evaluated using $\log -\log$ plots, which was satisfied [12]. Adjusted Cox regression analyses were performed, adjusting for statin treatment, antiplatelet treatment, oral anticoagulant treatment, and MI within 30 days after study inclusion (Model 1), and further adjusted for the following diabetes-related comorbidities: hypertension, peripheral artery disease, previous ischemic stroke, and chronic obstructive pulmonary disease (Model 2). For ischemic stroke and death, Model 2 also included heart failure, and atrial fibrillation. The general population was used as reference. Stata/MP 16 (StataCorp LLC, College Station, Texas, USA) was used for all analyses.

\section{Stratified analyses}

Participants were stratified according to sex. We also stratified diabetes patients by type of diabetes treatment (non-pharmacological treatment, non-insulin treatment, and insulin treatment \pm non-insulin treatment), and performed a stratified analysis by duration of diabetes ( $0-4$ years, $5-9$ years, $\geq 10$ years).

\section{Subgroup analyses}

A subgroup analysis was limited to diabetes patients referred for elective CAG with a procedural indication of stable angina pectoris, as well as to patients with an indication of acute coronary syndrome (ACS). We also performed a subgroup analysis in which we compared the diabetes cohort with individuals diagnosed with diabetes in the general population.

\section{Ethical considerations}

This study was approved by the Danish Data Protection Agency (record no. 1-16-02-193-18). Observational, non-interventional, registry-based studies do not 
require approval from ethics committees or informed consent from patients according to Danish regulations.

\section{Results}

A total of 5734 diabetes patients with no CAD as assessed by CAG were matched with 28,670 individuals from the Western Denmark general population (Fig. 1). Median follow-up time was 7.0 years (IQR 2.6-10.0 years).

\section{Baseline characteristics}

Median age was 62 years (Table 1). Diabetes patients primarily underwent CAG due to stable angina pectoris, valve disease, or cardiomyopathy. Diabetes patients were more often diagnosed with chronic pulmonary disease, hypertension, heart failure, and atrial fibrillation compared to the general population group. We observed that $7.1 \%$ of matched persons from the general population had diabetes. The CAG cohort of diabetes patients also was more frequently treated with anti-thrombotic agents, oral anti-coagulants, statins, and anti-hypertensive drugs.

\section{Medicine changes}

Aspirin treatment decreased by $1.1 \%$ after CAG compared to 6 months prior to the procedure (Table 2). However, this reflects that $13.0 \%$ of diabetes patients stopped redeeming aspirin prescriptions by 6 months post-CAG, while $11.9 \%$ of patients, who previously had not taken aspirin, initiated aspirin despite lack of obstructive CAD.

\section{Myocardial infarction}

Ten-year MI risks were low in both the diabetes cohort (3.2\%) and the matched general population comparison cohort $(2.9 \%)$ when accounting for death as a competing risk. Diabetes patients had a higher absolute 10-year MI incidence (RD 0.3\%, 95\% CI -0.3-0.9) (Table 3 and Fig. 2), but this small difference was no longer evident after adjusting for cardiovascular risk factors and prophylactic treatment (adjusted HR 0.93, 95\% CI 0.72-1.20). When stratifying by sex, men with diabetes had a lower risk of MI than men in the general population cohort, while women had a similar MI risk as women in the general population cohort (Fig. 3 and Additional file 1: Table S2).

\section{Ischemic stroke}

Ten-year ischemic stroke incidence was higher in the diabetes cohort (5.2\%) than in the matched general population cohort $(2.2 \%)$ when accounting for death as a competing risk. This corresponded to a RD of 3.0\% (95\% CI 2.3-3.7), a difference that was sustained after adjustment for potential confounders.

\section{Death}

Diabetes patients had higher mortality compared to the matched general population cohort (RD 11.8\%, 95\% 10.2-13.4). After adjusting for comorbidity and medical treatment, diabetes patients remained at increased risk of death compared to the matched general population cohort (adjusted HR 1.24, 95\% CI 1.13-1.36).

\section{Subgroup analyses}

When we restricted our analysis to diabetes patients with stable angina undergoing elective CAG, this subgroup had a low risk of both MI (adjusted HR 0.69, 95\% CI 0.46-1.04) and death (adjusted HR 0.83, 95\% CI 0.700.98 ) compared to their matched general population cohort. However, ischemic stroke risk remained elevated after adjustment (Fig. 3 and Additional file 1: Table S3). We also observed non-significant increases in risks of MI, ischemic stroke, and death in patients for whom ACS was the referral indication.

Type of diabetes treatment did not affect the risk of MI in the cohort of diabetes patients without obstructive CAD compared to the general population (Fig. 3 and Additional file 1: Table S4). Ischemic stroke risk and mortality were highest in diabetes patients treated with insulin and lowest in patients not receiving active pharmacological treatment compared to the general population (Fig. 3 and Additional file 1: Table S4). Duration of diabetes was associated with increased risk of MI, ischemic stroke, and death (Fig. 3 and Additional file 1: Table S5).

Compared to individuals from the general population with diabetes but no history of CAD, diabetes patients without CAD as assessed by CAG had a lower risk of MI and death and a similar risk of ischemic stroke (Additional file 1: Table S6).

\section{Discussion}

Among diabetes patients without obstructive CAD, the 10 -year risk of MI was only $0.3 \%$ higher than that observed in a general population comparison cohort, a difference which was no longer evident when the analysis was adjusted for comorbidity and use of prophylactic medications. Thus, a finding of no or mild CAD in diabetes patients undergoing CAG conferred an MI risk comparable to that for a general population comparison cohort. However, diabetes remained associated with increased risk of ischemic stroke and death despite absence of obstructive CAD and adjustment for comorbidity. Stratified analyses suggested that clinical presentation, diabetes treatment, and duration of diabetes were associated with relatively higher risks of ischemic stroke and death than observed in the matched general 
Table 1 Baseline characteristics of patients with diabetes and their matched general population comparison cohort

\begin{tabular}{|c|c|c|c|c|}
\hline & \multicolumn{2}{|c|}{ Diabetes patients $(n=5734)$} & \multicolumn{2}{|c|}{ General population $(n=28,670)$} \\
\hline & $\mathrm{N}$ & $\%$ & $\mathrm{~N}$ & $\%$ \\
\hline Male sex & 2997 & 52.3 & 14,985 & 52.3 \\
\hline Median age (IQR) & 62 years $(53-70)$ & & 62 years $(53-70)$ & \\
\hline \multicolumn{5}{|l|}{ Family history of ischemic heart disease ${ }^{a}$} \\
\hline Yes & 2058 & 35.9 & - & - \\
\hline Missing & 670 & 11.7 & - & - \\
\hline \multicolumn{5}{|l|}{ Smoking ${ }^{a}$} \\
\hline Active & 1070 & 18.7 & - & - \\
\hline Former & 2024 & 35.3 & - & - \\
\hline Never & 2008 & 35.0 & - & - \\
\hline Missing & 632 & 11.0 & - & - \\
\hline \multicolumn{5}{|l|}{ CAG procedural indication ${ }^{\mathrm{a}}$} \\
\hline STEMI & 112 & 2.0 & - & - \\
\hline NSTEMI & 259 & 4.5 & - & - \\
\hline Unstable AP & 190 & 3.3 & - & - \\
\hline Stable AP & 2666 & 46.5 & - & - \\
\hline Arrhythmia & 228 & 4.0 & - & - \\
\hline Valvular disease & 665 & 11.6 & - & - \\
\hline Cardiomyopathy & 613 & 10.7 & - & - \\
\hline Other & 899 & 15.7 & - & - \\
\hline Missing & 102 & 1.8 & - & - \\
\hline \multicolumn{5}{|l|}{ Comorbidity } \\
\hline Diabetes & 5734 & 100.0 & 2041 & 7.1 \\
\hline Chronic pulmonary disease & 626 & 10.9 & 1123 & 3.9 \\
\hline Hypertension & 3362 & 58.6 & 3110 & 10.8 \\
\hline Peripheral artery disease & 214 & 3.7 & 456 & 1.6 \\
\hline Heart failure & 991 & 17.3 & 262 & 0.9 \\
\hline Atrial fibrillation & 1070 & 18.7 & 979 & 3.4 \\
\hline Ischemic stroke & 201 & 3.5 & 285 & 1.0 \\
\hline Hemorrhagic stroke & 12 & 0.2 & 69 & 0.2 \\
\hline $\mathrm{Ml}<30$ days after inclusion & 2 & 0.0 & 6 & 0.0 \\
\hline \multicolumn{5}{|l|}{ Comedication } \\
\hline Aspirin & 3535 & 61.6 & 3455 & 12.1 \\
\hline ADP-inhibitors & 261 & 4.6 & 286 & 1.0 \\
\hline Vitamin K-antagonists & 909 & 15.9 & 830 & 2.9 \\
\hline DOAC & 182 & 3.2 & 148 & 0.5 \\
\hline Statin & 4140 & 72.2 & 5423 & 18.9 \\
\hline Beta-blocker & 3118 & 54.4 & 3227 & 11.3 \\
\hline ACE-inhibitor & 2659 & 46.4 & 3832 & 13.4 \\
\hline ARB & 1698 & 29.6 & 2870 & 10.0 \\
\hline Thiazide & 1209 & 21.1 & 2879 & 10.0 \\
\hline Calcium-blocker & 2050 & 35.8 & 3669 & 12.8 \\
\hline Insulin & 1631 & 28.4 & 568 & 2.0 \\
\hline Non-insulin anti-diabetes agents & 3658 & 63.8 & 1484 & 5.2 \\
\hline
\end{tabular}

$A C E$ angiotensin converting enzyme, $A D P$ adenosine diphosphate, $A P$ angina pectoris, $A R B$ angiotensin-II receptor blocker, $C A G$ coronary angiography, $D O A C$ direct oral anti-coagulant, MI myocardial infarction, NSTEMI non ST-elevation myocardial infarction, SD standard deviation, STEMI ST-elevation myocardial infarction

a Data provide by the Western Denmark Heart Registry. Unavailable for the general population 
Table 2 Change in medical treatment from 6 months before to 6 months after coronary angiography in diabetes patients without coronary artery disease and with $>6$ months of follow-up $(n=5661)$

\begin{tabular}{|c|c|c|c|c|c|}
\hline & Before $^{a}$ & After ${ }^{\mathbf{b}}$ & New users ${ }^{c}$ & Former users $^{d}$ & Net change ${ }^{e}( \pm)$ \\
\hline Aspirin & $55.1 \%$ & $53.9 \%$ & $11.9 \%$ & $13.0 \%$ & $-1.1 \%$ \\
\hline Statins & $66.6 \%$ & $70.0 \%$ & $9.4 \%$ & $6.0 \%$ & $+3.4 \%$ \\
\hline Adenosine diphosphate-inhibitors & $3.3 \%$ & $4.6 \%$ & $2.5 \%$ & $1.2 \%$ & $+1.3 \%$ \\
\hline Vitamin-K antagonist & $13.0 \%$ & $19.3 \%$ & $7.5 \%$ & $1.2 \%$ & $+6.3 \%$ \\
\hline Direct oral anti-coagulants & $2.3 \%$ & $3.7 \%$ & $1.7 \%$ & $0.4 \%$ & $+1.3 \%$ \\
\hline Beta-blockers & $46.5 \%$ & $52.6 \%$ & $13.0 \%$ & $6.9 \%$ & $+6.1 \%$ \\
\hline Angiotensin converting enzyme-inhibitors & $41.6 \%$ & $43.5 \%$ & $7.8 \%$ & $5.9 \%$ & $+1.9 \%$ \\
\hline Angiotensin-II receptor blockers & $28.4 \%$ & $29.2 \%$ & $4.2 \%$ & $3.4 \%$ & $+0.8 \%$ \\
\hline Thiazide & $19.4 \%$ & $18.1 \%$ & $4.5 \%$ & $5.8 \%$ & $-1.3 \%$ \\
\hline Calcium-blockers & $32.0 \%$ & $33.4 \%$ & $7.7 \%$ & $6.3 \%$ & $+1.4 \%$ \\
\hline Insulin & $27.0 \%$ & $29.9 \%$ & $3.8 \%$ & $0.9 \%$ & $+2.9 \%$ \\
\hline Non-insulin diabetes medication & $61.6 \%$ & $62.2 \%$ & $4.6 \%$ & $4.0 \%$ & $+0.6 \%$ \\
\hline
\end{tabular}

a Before: redeemed $\geq 1$ prescription within 6 months before angiography

b After: redeemed $\geq 1$ prescription within 6 months after angiography

c New user: redeemed $\geq 1$ prescription within 6 months after angiography, but not 6 months before

d Former user: redeemed $\geq 1$ prescription within 6 months before angiography, but not 6 months after

e Net change: overall change in prescriptions from before to after angiography

Table 3 Risk of myocardial infarction, ischemic stroke, and all-cause death in patients with diabetes and their matched general population comparison cohort

\begin{tabular}{|c|c|c|c|c|c|c|c|}
\hline & Patients & Events & $\begin{array}{l}10 \text {-year } \\
\text { cumulative } \\
\text { incidence }{ }^{\mathrm{a}}(95 \% \\
\mathrm{Cl})\end{array}$ & $\begin{array}{l}\text { Risk difference } \\
(95 \% \mathrm{Cl})\end{array}$ & $\begin{array}{l}\text { Unadjusted HR } \\
(95 \% \mathrm{Cl})\end{array}$ & $\begin{array}{l}\text { Adjusted HR }{ }^{\mathbf{b}}(95 \% \\
\text { Cl) }\end{array}$ & $\begin{array}{l}\text { Adjusted HR }{ }^{\mathrm{C}}(95 \% \\
\text { Cl) }\end{array}$ \\
\hline \multicolumn{8}{|l|}{ Myocardial infarction } \\
\hline $\begin{array}{l}\text { General popula- } \\
\text { tion }\end{array}$ & 28,670 & 595 & $2.9 \%(2.7-3.1)$ & Reference & Reference & Reference & Reference \\
\hline Diabetes patients & 5734 & 134 & $3.2 \%(2.7-3.8)$ & $0.3 \%(-0.3-0.9)$ & $1.26(1.04-1.52)$ & $1.07(0.84-1.36)$ & $0.93(0.72-1.20)$ \\
\hline \multicolumn{8}{|l|}{ Ischemic stroke } \\
\hline $\begin{array}{l}\text { General popula- } \\
\text { tion }\end{array}$ & 28,670 & 456 & $2.2 \%(2.0-2.4)$ & Reference & Reference & Reference & Reference \\
\hline Diabetes patients & 5734 & 230 & $5.2 \%(4.5-5.9)$ & $3.0 \%(2.3-3.7)$ & $2.96(2.51-3.50)$ & $2.04(1.65-2.52)$ & $1.87(1.47-2.38)$ \\
\hline \multicolumn{8}{|l|}{ Death } \\
\hline $\begin{array}{l}\text { General popula- } \\
\text { tion }\end{array}$ & 28,670 & 3659 & $17.8 \%(17.2-18.3)$ & Reference & Reference & Reference & Reference \\
\hline Diabetes patients & 5734 & 1228 & $29.6 \%(28.1-31.1)$ & $11.8 \%(10.2-13.4)$ & $1.88(1.76-2.01)$ & $1.58(1.45-1.72)$ & $1.24(1.13-1.36)$ \\
\hline
\end{tabular}

CAG coronary angiography, $C l$ confidence interval, CIP cumulative incidence proportion, $H R$ hazard ratio

a Limited to the 75th percentile of follow-up (10 years). In myocardial infarction and ischemic stroke, accounting for the competing risk of death

${ }^{\text {b }}$ Adjusted for myocardial infarction within 30 days of angiography, statin treatment, oral anticoagulant treatment, and antiplatelet treatment

c Adjusted for peripheral artery disease, hypertension, chronic obstructive pulmonary disease, myocardial infarction within 30 days of angiography, statin treatment, oral anticoagulant treatment, and antiplatelet treatment. In case of ischemic stroke and death, additionally adjusted for congestive heart failure, previous ischemic stroke/TIA, and atrial fibrillation

population cohort. Thus, while absence of CAD was associated with a low MI risk, diabetes patients had a higher risk of other cardiovascular outcomes, particularly in certain subgroups, despite more frequent treatment with preventive medications.
It has previously been shown that diabetes patients without obstructive CAD, as assessed by either CAG or coronary computed tomography angiography (CCTA), have similar MI risks as non-diabetes patients without CAD undergoing the same imaging procedures [2-4]. 


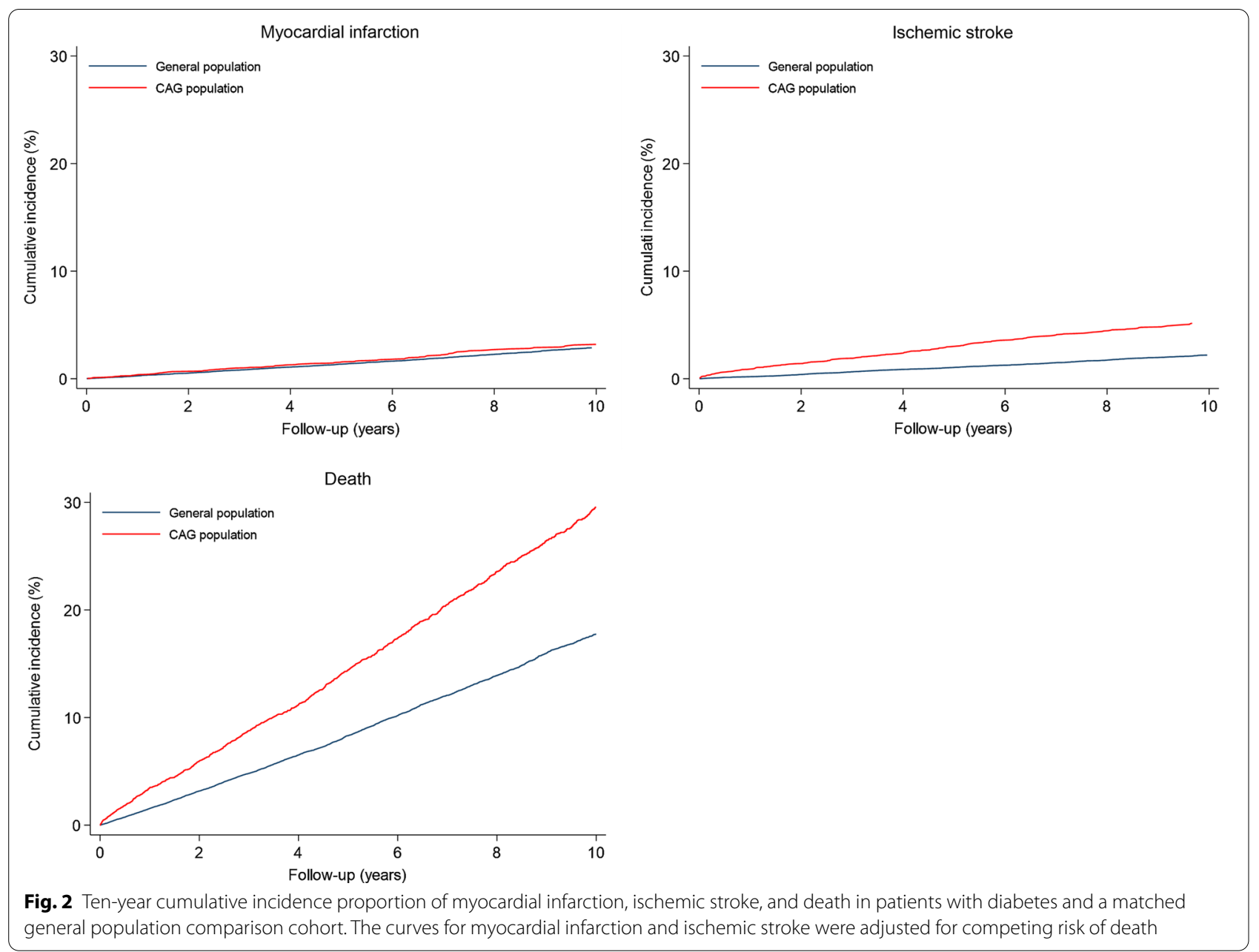

However, in earlier studies, the comparison group consisted of a selected group of symptomatic patients. It is unlikely that this group reflects the risk of $\mathrm{MI}$ in the general population without previous CAD. Our results therefore expand upon prior findings by showing that MI risk among diabetes patients is not only similar to that of non-diabetes patients undergoing CAG or CCTA, but also similar to that of a matched general population without known CAD. Of note, compared to individuals from the general population with diabetes, diabetes patients without CAD had a lower risk of both MI and death.

It is important to underscore that the risk of ischemic stroke was doubled in the diabetes cohort compared with the general population, despite lack of significant CAD. Moreover, the 10-year risk of ischemic stroke was higher (5\%) than the risk of MI (3\%). This is consistent with a recent report that also found that diabetes patients without angiographic CAD were at elevated risk of ischemic stroke [13]. The control group differed from this study, consisting of non-diabetes patients undergoing CAG
[13]. These results may reflect thromboembolic events rather than manifestations of carotid and cerebral atherosclerotic disease, which again may be related to a higher prevalence of obesity in patients with diabetes [14].

Certain subgroups of diabetes patients were at increased cardiovascular risk despite lack of obstructive CAD. Referral for CAG due to suspected ACS, insulin treatment, and duration of diabetes were all associated with poor prognosis after the examination. Diabetes duration increases stroke risk by $3 \%$ per year [15]. While screening of asymptomatic high-risk diabetes patients is not currently recommended, asymptomatic patients with diabetes duration $>10.5$ years may benefit from non-invasive angiographic screening $[16,17]$. Insulin treatment has also been associated with increased stroke risk and higher mortality $[13,15,18,19]$. These associations also apply to diabetes patients without obstructive CAD, as assessed by CAG, compared to the general population. Male diabetes patients without CAD had a lower relative risk of MI, while female patients had higher relative risk 


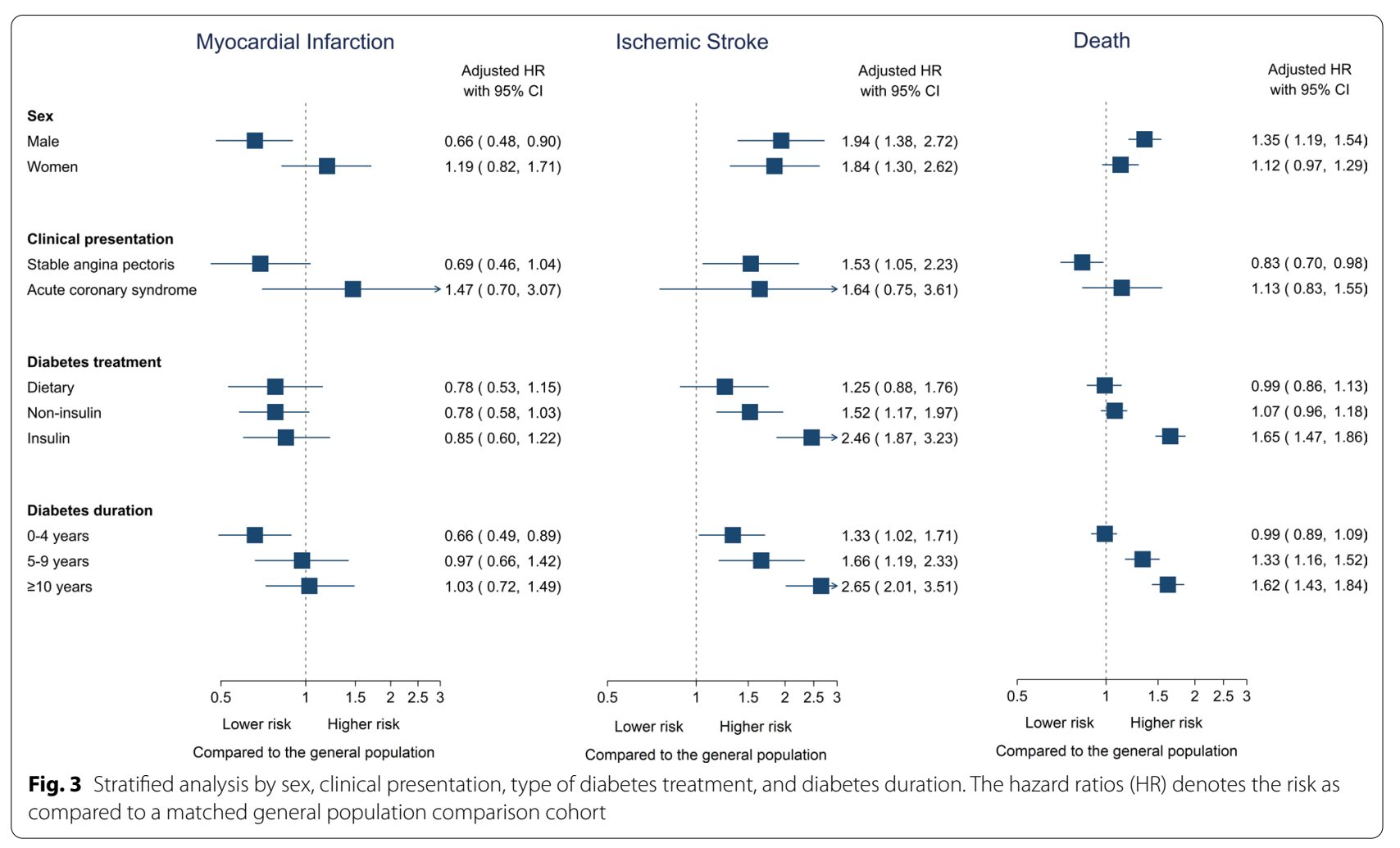

compared to same-sex members of the general population. However, this reflects sex-related difference in MI risk in the general population, where women $(2.1 \%)$ are at a much lower risk than men $(4.3 \%)$. The absolute risk was more similar among men and women after CAG $(3.9 \%$ vs $3.6 \%)$ in the absence of CAD. Meta-analyses differ on whether sex affects cardiovascular risk in diabetes patients with established cardiovascular disease compared to non-diabetes patients [20, 21]. Among diabetes patients without obstructive CAD, we did not find clinical differences between sexes.

We observed a small net decrease of $1.1 \%$ in aspirin treatment after CAG, as $13 \%$ of all diabetes patients without CAD discontinued aspirin treatment and 12\% initiated treatment after CAG. To some extent, this finding reflects initiation of aspirin during acute hospitalizations due to suspicion of acute coronary syndrome. It is common that aspirin treatment is continued following CAG. Still, more than half of diabetes patients without CAD were treated with aspirin after CAG. The relatively low prevalence of other vascular comorbidities [peripheral artery disease (3.7\%) and ischemic stroke (3.5\%)] cannot account for the continued high use of aspirin in these patients. With a $0.3 \%$ and $2.6 \% 10$-year RD of MI and ischemic stroke compared to the general population, respectively, diabetes patients without obstructive CAD may not require continued antithrombotic treatment unless otherwise indicated. Recent randomized clinical trials have questioned the role of aspirin in primary cardiovascular prevention [22, 23]. The ASCEND (A Study of Cardiovascular Events iN Diabetes) trial randomized 15,480 diabetes patients without a previous history of cardiovascular disease to either aspirin or placebo [22]. While aspirin reduced a composite of serious vascular events (MI, ischemic stroke, transient ischemic attack, and cardiovascular death) by $1.1 \%$, aspirin had no impact on MI risk (HR 0.98, 95\% CI 0.80-1.19). The reduction in cardiovascular events was offset by a $0.9 \%$ increase in major bleeding. Further, a large meta-analysis of 23,488 diabetes patients found no effect of aspirin in primary prevention of MI (HR 0.94, 95\% CI 0.83-1.07), while significantly increasing major bleeding risk (HR 1.29, 95\% CI 1.11-1.5) [24]. The American Diabetes Association does not recommend primary prevention with aspirin, except in high-risk diabetes patients with an acceptably low bleeding risk [25]. European guidelines suggest a similar approach in recommending aspirin accompanied by prophylactic proton pump inhibition in 'high' and 'very high' risk diabetes patients without previous vascular disease [26]. The high rate of aspirin treatment in diabetes patients at documented low risk of MI may confer a bleeding risk rather than add protection against future ischemic events. Statin therapy is recommended to most patients with diabetes, and have in observational studies 
been found to reduce MI, cardiac death, and all-cause mortality in patients without obstructive CAD by CCTA [27-29]. Continued statin treatment should be considered in diabetes patients despite absence of obstructive CAD.

Patients registered with 0 -vessel disease in the Western Denmark Heart Registry have either no CAD or non-obstructive $\mathrm{CAD}$ in a single vessel, but the registry does not differentiate between the two conditions. A large American cohort study found no difference in 1-year MI risk between diabetes patients with no apparent $C A D$ versus diabetes patients with non-obstructive single vessel disease [30]. However, patient-level differences in non-obstructive plaque extent could potentially be used in additional risk stratification of diabetes patients without obstructive CAD [31]. CCTA can be used to identify diabetes patients with an incremental risk of cardiovascular disease based on CAD severity [3, 32]. Non-obstructive CAD is associated with coronary microvascular dysfunction, particularly in women with poor glycemic control, which significantly increases the risk of major adverse cardiovascular events [33-35]. Diabetes increases cardiovascular risk in patients with nonobstructive CAD and ACS, supporting our results in which diabetes patients referred to CAG with ACS had increased risk of cardiovascular outcomes compared to the general population $[36,37]$.

\section{Limitations}

Our observational study provides data on the cardiovascular risk in Danish patients with diabetes compared to the Danish general population. The results, however, may not be representative for patients with diabetes or general population individuals in other countries with different health care systems and ethnicities. We did not have access to HbA1c measurements, which have been found to correlate with cardiovascular risk [38]. However, intensive glucose control has not been found uniformly to reduce cardiovascular risk [39-41]. Another concern is that our reference cohort consisted of a random sample of individuals from the Western Denmark general population without known coronary artery disease, but some may in fact have significant CAD. Hence, comparing angiographic absence of CAD with lack of diagnosed CAD reflects a clinical approach rather than an assumption of similar extent of CAD.

\section{Conclusions}

In conclusion, diabetes patients without $\mathrm{CAD}$ as assessed by CAG had a similar risk of MI, but an increased risk of ischemic stroke and death, compared to a general population cohort. Medical treatment of diabetes, especially with insulin, and long duration of diabetes may exacerbate the risk of ischemic stroke and death compared to that experienced by a general population cohort. Despite absence of obstructive CAD and a low risk of MI, diabetes still remains associated with other cardiovascular outcomes.

\section{Supplementary information}

The online version contains supplementary material available at https://doi. org/10.1186/s12933-021-01212-x.

Additional file 1: Table S1. International Classification of Diseases (ICD) from the Danish National Patient Registry [7]. Table S2. Risk of myocardial infarction, ischemic stroke, and all-cause death stratified by sex. Table S3. Risk of myocardial infarction, ischemic stroke, and all-cause death stratified in patients referred with stable angina pectoris and acute coronary syndrome. Table S4. Risk of myocardial infarction, ischemic stroke, and all-cause death in diabetes patients stratified by type of diabetes treatment and the general population. Table S5. Risk of myocardial infarction, ischemic stroke, and all-cause death in diabetes patients without coronary artery disease by duration of diabetes treatment. Table S6. Risk of myocardial infarction, ischemic stroke, and all-cause death compared to individuals from the general population with diabetes.

\section{Abbreviations}

ASCEND: A Study of Cardiovascular Events iN Diabetes; ACS: Acute coronary syndrome; CABG: Coronary artery bypass grafting; CAG: Coronary angiography; CAG: Coronary artery disease; CCTA: Coronary computed tomography angiography; CIP: Cumulative incidence proportion; MI: Myocardial infarction; $\mathrm{PCl}$ : Percutaneous coronary intervention; RD: Risk difference.

\section{Acknowledgements}

Not applicable.

\section{Authors' contributions}

All authors conceptualized the study. Dr. Olesen, Mr. Madsen, and Dr. Maeng designed the study. Dr. Olesen was responsible for data acquisition, data management and analysis. All authors contributed to data interpretation. Dr. Olesen wrote the first draft of the manuscript. All authors provided significant revision of the manuscript and gave final approval for publication. All authors read and approved the final manuscript.

\section{Funding}

This study was funded by the Department of Cardiology, Aarhus University Hospital, Aarhus, Denmark.

\section{Availability of data and materials \\ According to Danish data protection regulations, data cannot be made publicly available.}

\section{Ethics approval and consent to participate}

The study was approved by a regional branch of the Danish Data Protection Agency (record no. 1-16-02-193-18). Registry-based studies do not require approval from ethics committees or informed consent from participants according to Danish regulation.

\section{Consent for publication}

Informed consent is not required from participants in registry-based, noninterventional cohort studies according to Danish regulation.

\section{Competing interests}

Dr. Olesen has received a speaking fee from Bayer. Dr. Thrane, Dr. Gyldenkerne, Dr. Thim, and Professor Bøtker have no conflicts of interest. Mr. Madsen and Professor Sørensen has not received any personal fees, grants, travel grants, or teaching grants from companies. Department of Clinical Epidemiology is, however, involved in studies with funding from various companies as research grants to and administered by Aarhus University. None of these studies are 
related to the current study. Professor Jensen has received unrestricted grants to Department of Cardiology Odense University Hospital from Biotronik and Biosensors. Dr. Maeng has received advisory board fees from Boehringer-Ingelheim, AstraZeneca, Novo Nordisk, BMS, Boston Scientific, and Bayer.

\section{Author details}

1 Department of Cardiology, Aarhus University Hospital, Palle Juul-Jensens Boulevard 99, 8200 Aarhus N, Denmark. ${ }^{2}$ Department of Clinical Epidemiology, Aarhus University Hospital, Olof Palmes Allé 43-45, Aarhus N 8200, Denmark. ${ }^{3}$ Department of Cardiology, Viborg Regional Hospital, Heibergs Allé 4A, Viborg 8800, Denmark. ${ }^{4}$ Department of Cardiology, Odense University Hospital, J.B. Winsløws Vej 4, Odense 5000, Denmark.

Received: 6 October 2020 Accepted: 1 January 2021

Published online: 21 January 2021

\section{References}

1. Folsom AR, Szklo M, Stevens J, Liao F, Smith R, Eckfeldt JH. A prospective study of coronary heart disease in relation to fasting insulin, glucose, and diabetes. The Atherosclerosis Risk in Communities (ARIC) Study. Diabetes Care. 1997;20(6):935-42.

2. Olesen KKW, Madsen M, Egholm G, Thim T, Jensen LO, Raungaard B, Botker HE, Sorensen HT, Maeng M. Patients with and without diabetes without significant angiographic coronary artery disease have the same risk of myocardial infarction in a real-world population receiving appropriate prophylactic treatment. Diabetes care. 2017;40(8):1103-1110.

3. Olesen KKW, Riis AH, Nielsen LH, Steffensen FH, Nørgaard BL, Jensen JM, Poulsen PL, Thim T, Bøtker HE, Sørensen HT, et al. Risk stratification by assessment of coronary artery disease using coronary computed tomography angiography in diabetes and non-diabetes patients: a study from the Western Denmark Cardiac Computed Tomography Registry. Eur Heart J Cardiovasc Imaging. 2019;20(11):1271-8.

4. Saely CH, Aczel S, Marte T, Langer P, Drexel H. Cardiovascular complications in Type 2 diabetes mellitus depend on the coronary angiographic state rather than on the diabetic state. Diabetologia. 2004;47(1):145-6.

5. Schmidt M, Maeng M, Madsen M, Sorensen HT, Jensen LO, Jakobsen CJ. The Western Denmark Heart Registry: its Influence on Cardiovascular Patient Care. J Am Coll Cardiol. 2018;71(11):1259-72.

6. Schmidt M, Pedersen L, Sorensen HT. The Danish Civil Registration System as a tool in epidemiology. Eur J Epidemiol. 2014;29(8):541-9.

7. Schmidt M, Schmidt SA, Sandegaard JL, Ehrenstein V, Pedersen L, Sorensen HT. The Danish National Patient Registry: a review of content, data quality, and research potential. Clin Epidemiol. 2015;7:449-90.

8. Pottegard A, Schmidt SAJ, Wallach-Kildemoes H, Sorensen HT, Hallas J, Schmidt M. Data Resource Profile: the Danish National Prescription Registry. Int J Epidemiol. 2017;46(3):798-798f.

9. Stuart EA. Matching methods for causal inference: a review and a look forward. Stat Sci. 2010;25(1):1-21.

10. Egholm G, Madsen M, Thim T, Schmidt M, Christiansen EH, Botker HE, Maeng M. Evaluation of algorithms for registry-based detection of acute myocardial infarction following percutaneous coronary intervention. Clin Epidemiol. 2016;8:415-23.

11. Krarup LH, Boysen $G$, Janjua $H$, Prescott $E$, Truelsen T. Validity of stroke diagnoses in a National Register of Patients. Neuroepidemiology. 2007;28(3):150-4.

12. Zou G. A modified poisson regression approach to prospective studies with binary data. Am J Epidemiol. 2004;159(7):702-6.

13. Olesen KKW, Madsen M, Gyldenkerne C, Thrane PG, Würtz M, Thim T, Jensen LO, Eikelboom J, Bøtker HE, Sørensen HT et al: Diabetes Mellitus Is Associated With Increased Risk of Ischemic Stroke in Patients With and Without Coronary Artery Disease. Stroke. 2019;50(12):3347-54.

14. Bhupathiraju SN, Hu FB. Epidemiology of obesity and diabetes and their cardiovascular complications. Circ Res. 2016;118(11):1723-35.

15. Banerjee C, Moon YP, Paik MC, Rundek T, Mora-McLaughlin C, Vieira JR, Sacco RL, Elkind MS. Duration of diabetes and risk of ischemic stroke: the Northern Manhattan Study. Stroke Journal Cerebral Circulation. 2012;43(5):1212-7.
16. American Diabetes Association: 10. Cardiovascular Disease and Risk Management: Standards of Medical Care in Diabetes-2020. Diabetes Care 2020, 43(Supplement 1):S111-S134.

17. Venuraju SM, Lahiri A, Jeevarethinam A, Cohen M, Darko D, Nair D, Rosenthal M, Rakhit RD. Duration of type 2 diabetes mellitus and systolic blood pressure as determinants of severity of coronary stenosis and adverse events in an asymptomatic diabetic population: PROCEED study. Cardiovasc Diabetol. 2019;18(1):51.

18. Khalangot M, Tronko M, Kravchenko V, Kulchinska J, Hu G. The joint effects of different types of glucose-lowering treatment and duration of diabetes on total and cardiovascular mortality among subjects with type 2 diabetes. Diabetes Res Clin Pract. 2008:82(1):139-47.

19. Patti G, Lucerna M, Cavallari I, Ricottini E, Renda G, Pecen L, Romeo F, Le Heuzey JY, Zamorano JL, Kirchhof P, et al. Insulin-Requiring Versus Noninsulin-Requiring Diabetes and Thromboembolic Risk in Patients With Atrial Fibrillation: PREFER in AF. J Am Coll Cardiol. 2017;69(4):409-19.

20. Lee C, Joseph L, Colosimo A, Dasgupta K. Mortality in diabetes compared with previous cardiovascular disease: a gender-specific meta-analysis. Diab Metab. 2012;38(5):420-7.

21. Kanaya AM, Grady D, Barrett-Connor E. Explaining the sex difference in coronary heart disease mortality among patients with type 2 diabetes mellitus: a meta-analysis. Arch Intern Med. 2002;162(15):1737-45.

22. Bowman L, Mafham M, Wallendszus K, Stevens W, Buck G, Barton J, Murphy K, Aung T, Haynes R, Cox J, et al. Effects of Aspirin for Primary Prevention in Persons with Diabetes Mellitus. N Engl J Med. 2018;379(16):1529-39.

23. Gaziano JM, Brotons C, Coppolecchia R, Cricelli C, Darius H, Gorelick PB, Howard G, Pearson TA, Rothwell PM, Ruilope LM, et al. Use of aspirin to reduce risk of initial vascular events in patients at moderate risk of cardiovascular disease (ARRIVE): a randomised, double-blind, placebocontrolled trial. Lancet. 2018:392(10152):1036-46.

24. Zheng SL, Roddick AJ. Association of Aspirin Use for Primary Prevention With Cardiovascular Events and Bleeding Events. JAMA. 2019;321(3):277.

25. Cardiovascular Disease and Risk Management: Standards of Medical Care in Diabetes-2019. Diabetes Care 2019, 42(Suppl 1):S103-s123.

26. Cosentino F, Grant PJ, Aboyans V, Bailey CJ, Ceriello A, Delgado V, Federici M, Filippatos G, Grobbee DE, Hansen TB et al: 2019 ESC Guidelines on diabetes, pre-diabetes, and cardiovascular diseases developed in collaboration with the EASD: The Task Force for diabetes, pre-diabetes, and cardiovascular diseases of the European Society of Cardiology (ESC) and the European Association for the Study of Diabetes (EASD). Eur Heart J 2019.

27. Hulten E, Bittencourt MS, Singh A, O'Leary D, Christman MP, Osmani W, Abbara S, Steigner ML, Truong QA, Nasir K, et al. Coronary artery disease detected by coronary computed tomographic angiography is associated with intensification of preventive medical therapy and lower low-density lipoprotein cholesterol. Circulation Cardiovascular Imaging. 2014;7(4):629-38.

28. Hwang IC, Jeon JY, Kim Y, Kim HM, Yoon YE, Lee SP, Kim HK, Sohn DW, Sung J, Kim YJ. Statin therapy is associated with lower all-cause mortality in patients with non-obstructive coronary artery disease. Atherosclerosis. 2015;239(2):335-42.

29. Cho YK, Nam CW, Koo BK, Schulman-Marcus J, Hartaigh B, Gransar H, Lu Y, Achenbach S, Al-Mallah M, Andreini D, et al. Usefulness of baseline statin therapy in non-obstructive coronary artery disease by coronary computed tomographic angiography: From the CONFIRM (COronary CT Angiography EvaluatioN For Clinical Outcomes: An InteRnational Multicenter) study. PLoS ONE. 2018;13(12):e0207194.

30. Maddox TM, Stanislawski MA, Grunwald GK, Bradley SM, Ho PM, Tsai TT, Patel MR, Sandhu A, Valle J, Magid DJ, et al. Nonobstructive coronary artery disease and risk of myocardial infarction. JAMA. 2014;312(17):1754-63.

31. Bittencourt MS, Hulten E, Ghoshhajra B, O'Leary D, Christman MP, Montana P, Truong QA, Steigner M, Murthy VL, Rybicki FJ, et al. Prognostic value of nonobstructive and obstructive coronary artery disease detected by coronary computed tomography angiography to identify cardiovascular events. Circ Cardiovasc Imaging. 2014;7(2):282-91.

32. Finck T, Will A, Hendrich E, Martinoff S, Hadamitzky M. Coronary computed tomography angiography as a tool for long-term cardiovascular risk stratification in diabetic patients. Heart Vessels. 2019;34(7):1086-95. 
33. Sara JD, Taher R, Kolluri N, Vella A, Lerman LO, Lerman A. Coronary microvascular dysfunction is associated with poor glycemic control amongst female diabetics with chest pain and non-obstructive coronary artery disease. Cardiovasc Diabetol. 2019;18(1):22.

34. Sara JD, Widmer RJ, Matsuzawa Y, Lennon RJ, Lerman LO, Lerman A. Prevalence of coronary microvascular dysfunction among patients with chest pain and nonobstructive coronary artery disease. jacc cardiovasc interv. 2015;8(11):1445-53.

35. Gdowski MA, Murthy VL, Doering M, Monroy-Gonzalez AG, Slart R, Brown $\mathrm{DL}$. Association of isolated coronary microvascular dysfunction with mortality and major adverse cardiac events: a systematic review and meta-analysis of aggregate data. J Am Heart Assoc. 2020;9(9):e014954.

36. Nordenskjöld AM, Baron T, Eggers KM, Jernberg T, Lindahl B. Predictors of adverse outcome in patients with myocardial infarction with non-obstructive coronary artery (MINOCA) disease. Int J Cardiol. 2018;261:18-23.

37. Marfella R, Sardu C, Calabrò P, Siniscalchi M, Minicucci F, Signoriello G, Balestrieri ML, Mauro C, Rizzo MR, Paolisso G, et al. Non-ST-elevation myocardial infarction outcomes in patients with type 2 diabetes with non-obstructive coronary artery stenosis: Effects of incretin treatment. Diabetes Obes Metab. 2018;20(3):723-9.
38. Cavero-Redondo I, Peleteiro B, Álvarez-Bueno C, Rodriguez-Artalejo F, Martínez-Vizcaíno V. Glycated haemoglobin A1c as a risk factor of cardiovascular outcomes and all-cause mortality in diabetic and nondiabetic populations: a systematic review and meta-analysis. BMJ Open. 2017;7(7):e015949.

39. Intensive blood-glucose control with sulphonylureas or insulin compared with conventional treatment and risk of complications in patients with type 2 diabetes (UKPDS 33). UK Prospective Diabetes Study (UKPDS) Group. Lancet 1998, 352(9131):837-853.

40. Holman RR, Paul SK, Bethel MA, Matthews DR, Neil HAW. 10-Year follow-up of intensive glucose control in type 2 diabetes. N Engl J Med. 2008;359(15):1577-89.

41. Patel A, MacMahon S, Chalmers J, Neal B, Billot L, Woodward M, Marre M, Cooper M, Glasziou P, Grobbee D, et al. Intensive blood glucose control and vascular outcomes in patients with type 2 diabetes. N Engl J Med. 2008;358(24):2560-72.

\section{Publisher's Note}

Springer Nature remains neutral with regard to jurisdictional claims in published maps and institutional affiliations.
Ready to submit your research? Choose BMC and benefit from:

- fast, convenient online submission

- thorough peer review by experienced researchers in your field

- rapid publication on acceptance

- support for research data, including large and complex data types

- gold Open Access which fosters wider collaboration and increased citations

- maximum visibility for your research: over 100M website views per year

At BMC, research is always in progress.

Learn more biomedcentral.com/submissions 